\title{
Ki-67 labeling index affects tumor infiltration patterns of lung squamous cell carcinoma
}

\author{
DAISUKE MASUDA $^{1}$, RYOTA MASUDA ${ }^{1}$, TOMOHIKO MATSUZAKI ${ }^{1}$, NAOKO IMAMURA $^{1}$, \\ NAOHIRO ARUGA ${ }^{1}$, MAKIKO TANAKA $^{2}$, SADAKI INOKUCHI ${ }^{2}$, \\ HIROSHI KIJIMA $^{2,3}$ and MASAYUKI IWAZAKI ${ }^{1}$ \\ ${ }^{1}$ Department of General Thoracic Surgery, Tokai University School of Medicine, Isehara, Kanagawa 259-1193; \\ ${ }^{2}$ Department of Pathology and Bioscience, Hirosaki University Graduate School of Medicine, Hirosaki, \\ Aomori 036-8562; ${ }^{3}$ Department of Critical Care and Emergency Medicine, \\ Tokai University School of Medicine, Isehara, Kanagawa 259-1193, Japan
}

Received April 27, 2014; Accepted January 9, 2015

DOI: $10.3892 / \mathrm{mmr} .2015 .4354$

\begin{abstract}
Ki-67 is a nuclear protein that is expressed during the $G_{1}, S, G_{2}$ and $M$ phases of the mitotic cell cycle. A previous study categorized tumor infiltration patterns (INF), of which INFc indicated cancer nests exhibiting infiltrative growth and an unclear boundary between tumor tissue and surrounding healthy tissue. The present study used the Ki-67 labeling index (Ki-67 LI) as an indicator of cell proliferation, in order to examine the factors affecting INF in lung squamous cell carcinoma (SqCC). SqCC specimens (89) were classified into two groups: High-grade cell proliferation (Ki-67 LI $\geq 30 \%$ ) and low-grade cell proliferation ( $\mathrm{Ki}-67 \mathrm{LI}<30 \%$ ). However, a high Ki-67 LI was significantly associated with cases that had an INFc component [INFc(+); $\mathrm{P}=0.03]$. Univariate analyses indicated that $\mathrm{INFc}(+)$ was a predictor of venous invasion $[\mathrm{P}=0.032$; odds ratio (OR), 2.615; 95\% confidence interval (95\% CI), 1.085-6.305], scirrhous stromal type $(\mathrm{P}<0.001$; OR, 6.462; 95\% CI, 2.483-16.817) and high Ki-67 LI $(\mathrm{P}=0.018$; OR, 12.543; 95\% CI, 1.531-102.777). Multivariate logistic analyses indicated that high Ki-67 LI was the strongest predictor of INFc(+) $(\mathrm{P}=0.028$; OR, 8.027; 95\% CI, 1.248-51.624). In conclusion, high-grade cell proliferation activity may contribute to aggressive infiltrative growth of lung SqCC.
\end{abstract}

\section{Introduction}

Lung cancer is the most common type of cancer and it is the leading cause of cancer-related mortality worldwide (1). The

Correspondence to: Dr Hiroshi Kijima, Department of Pathology and Bioscience, Hirosaki University Graduate School of Medicine, 5 Zaifu-cho, Hirosaki, Aomori 036-8562, Japan

E-mail: hkijima@hirosaki-u.ac.jp

Key words: lung cancer, squamous cell carcinoma, Ki-67 labeling index, tumor infiltration prognosis for patients with lung cancer is generally poor, even following complete surgical resection (2), with recurrence rates of $15-30 \%$ and 5-year survival rates of $60-70 \%$ (3). There is an increasingly broad range of therapeutic options for recurrent or unresectable lung adenocarcinoma, for example, customized chemotherapy $(4,5)$ and molecular-targeted therapies, including bevacizumab $(6,7)$, erlotinib $(4,8)$ and gefitinib (4). By contrast, there are few therapeutic options for recurrent lung SqCC. Therefore, accurate prognostic indicators for patients with lung SqCC are required.

Recent studies have demonstrated immunohistochemical expression patterns of cell-cycle-related molecules in lung cancer, such as p53, retinoblastoma protein, cyclin D1, p27 and $\mathrm{Ki}-67$ (9-13). $\mathrm{Ki}-67$ is a nuclear protein that is expressed during the $G_{1}, S, G_{2}$ and $M$ phases of the mitotic cell cycle, although it is not expressed during the non-mitotic $\mathrm{G}_{0}$ phase (14-17). The genetic locus of Ki-67 has not yet been characterized. However, it has been assigned to chromosome 10. A number of studies have demonstrated that cell proliferative activity, as indicated by the Ki-67 labeling index (Ki-67 LI), correlates with cell growth (14-17). However, to the best of our knowledge there have been no investigations into the association between $\mathrm{Ki}-67 \mathrm{LI}$ and lung cancer tumor growth patterns.

Using the general criteria for esophageal and gastric cancer studies (18-25), the tumor infiltration patterns (INF) of lung SqCC have been classified into two groups: Lung tissue specimens with and without clear boundaries between tumor tissue and healthy surrounding tissue, which are termed INFc(-) and $\mathrm{INFc}(+)$ respectively (24). Masuda et al (24) demonstrated that $\mathrm{INFc}(+)$ was significantly associated with venous invasion, the scirrhous stromal tumor type and a lower postoperative survival in patients with lung $\mathrm{SqCC}$. Therefore, INFc(+) may be a useful indicator for the level of local aggressiveness and invasiveness of lung SqCC.

In the present study, the association between INF components and immunohistochemical Ki-67 LI was analyzed. The present study also investigated the clinicopathological significance of cell proliferation and tumor invasiveness at the invasive front of lung SqCCs. 


\section{Materials and methods}

Lung cancer specimens.Cancertissue specimens were obtained from surgically resected lung SqCC tissue following obtaining informed consent from 89 patients ( 85 males and four females; age range, $43-85$ years; mean age, $67.2 \pm 0.9$ years). The study was approved by the ethics committee of the Institutional Review Board of Tokai University Hospital (Isehara, Japan). All patients had undergone radical surgery (lobectomy and mediastinal lymphadenectomy) at Tokai University Hospital between January 2001 and December 2006. Tumor stages were defined according to the TNM classification of the International Union Against Cancer (UICC; 5), and the histological types were defined according to the World Health Organization classification (26). The median postoperative follow-up duration was 1,572 days (range 41-3,837 days).

Histological examination. Lung tissue specimens were immediately fixed with $10 \%$ buffered formalin for $24-48 \mathrm{~h}$ and embedded in paraffin (Wako Pure Chemical. Industries Ltd., Osaka, Japan). Tissue samples were cut at 5-10 $\mathrm{mm}$ intervals. Tumor invasion and lymphatic invasion were examined in $4-\mu \mathrm{m}$ sections, that were stained with hematoxylin and eosin. The extent of lymphatic invasion in the tissue specimens was classified as follows: ly0, no lymphatic invasion; ly1+, mild lymphatic invasion; ly $2+$, moderate lymphatic invasion; and ly3+, severe lymphatic invasion. Vascular and pleural invasion was evaluated using Elastica van Gieson staining for detection of elastic fibres. The degree of venous invasion in the tissue specimens was classified as follows: v0, no venous invasion; $\mathrm{v} 1+$, minimal venous invasion (one or two foci of venous invasion in one histological section); v2+, moderate venous invasion (three or four foci); or v3+, severe venous invasion (five or more foci).

INF at the invasive front of the SqCC was classified into three groups according to the general criteria for gastric cancer studies $(18-20,24)$ : INFa, cancer nests exhibit expanding growth and a distinct boundary with the surrounding tissue; $\mathrm{INFb}$, the manner of growth and invasive pattern is intermediate between those of INFa and INFc; and INFc, cancer nests exhibit infiltrative growth without a clear boundary between the tumor tissue and surrounding healthy tissue. However, a number of samples exhibited intermediate characteristics, for example, $\mathrm{INFa}>\mathrm{b}(5,20,27)$. Therefore, $\mathrm{SqCC}$ tissue specimens were further classified into seven categories: INFa, INFa $>b$, $I N F a<b, I N F b, I N F b>c, I N F b<c$ and INFc. These seven categories were allocated into two broader groups: Those cases with an INFc component $[\mathrm{INFc}(+)$; comprising INFb $>\mathrm{c}$, $\mathrm{INFb}<\mathrm{c}$ and $\mathrm{INFc}]$, and those without an INFc component [INFc (-); comprising INFa, INFa $>b$, INFa $<b$ and INFb].

The stromal types, that is, cancer cells/stroma (c/s) ratio in the cancerous lesion were also classified into three groups: Medullary type, the stroma is limited (high c/s ratios); intermediate type, the quantity of stroma is intermediate between those of the scirrhous and medullary types (intermediate $\mathrm{c} / \mathrm{s}$ ratios); and scirrhous type, the stroma is abundant (low c/s ratios) t (19).

Immunohistochemical analysis. Deparaffinized and dehydrated $4-\mu \mathrm{m}$ paraffin sections were immersed in
$0.3 \%$ hydrogen peroxide $\left(\mathrm{H}_{2} \mathrm{O}_{2}\right)$ in methanol (Wako Pure Chemical. Industries Ltd.) for $30 \mathrm{~min}$ in order to abolish endogenous peroxidase activity. Subsequently, the sections were mounted on aminoacyl silane-coated glass slides and used for immunohistochemical analysis of Ki-67 expression (Ki-67; rabbit monoclonal; cat. no. 418071; Nichirei Bioscience, Tokyo, Japan). In order to facilitate Ki-67 antigen retrieval, the sections were penetrated by autoclave heating (ES-215, High-pressure steam sterilizer; Tomy Seiko Co., LTD, Tokyo, Japan) at $121^{\circ} \mathrm{C}$ for $4 \mathrm{~min}$. Non-specific binding was abolished using diluted normal sheep serum (Cosmo Bio Co., Ltd, Tokyo, Japan). Subsequently, a primary monoclonal antibody, diluted 1:100 in 1\% bovine serum albumin (Wako Pure Chemical. Industries Ltd.) and phosphate-buffered saline (PBS), was added and incubated overnight at $4^{\circ} \mathrm{C}$ in a moist chamber. Following a wash phase using PBS, a secondary anti-rabbit IgG peroxidase-linked antibody (cat. no. NA934) at 1:100 dilution (Amersham International plc., Little Chalfont, UK) was applied for $60 \mathrm{~min}$ at room temperature. The sections were then treated with streptavidin-conjugated horseradish peroxidase for $30 \mathrm{~min}$ at room temperature (Funakoshi Co., Ltd., Tokyo, Japan). The reaction products were visualized using diaminobenzidine tetrahydrochloride (Muto Pure Chemicals Co., Ltd., Tokyo, Japan) for $4 \mathrm{~min}$ in Tris buffer.

Evaluation of Ki-67 LI. Cells were observed using a 40x objective microscope (BX50; Olympus, Tokyo, Japan). In each section, $\leq 1,000$ cells were randomly selected and the positive cells were counted. The cut-off point for positivity was considered when $\geq 30 \%$ positive cells were observed. Samples were classified into two groups: high-grade cell proliferation (Ki-67 LI $\geq 30 \%$ ) and low-grade cell proliferation (Ki-67 LI <30\%).

Statistical analysis. Univariate analyses (chi-square tests) were primarily used for identifying all variables that exhibited statistically significant differences. $\mathrm{P}<0.05$ was considered to indicate a statistically significant difference. Cox proportional hazards regression analysis was conducted in order to determine the effect of each predictor variable, using univariate analyses. Univariate and multivariate analyses were conducted in order to investigate the association between $\mathrm{Ki}-67 \mathrm{LI}$ and $\mathrm{SqCC}$ tumor invasion. Propensity scores were calculated in the multivariate analysis, in order to measure the effect of the following covariates on $\operatorname{INFc}(+)$ : Age at surgery, gender, tumor size, lymph node metastasis, lymphatic invasion, histological differentiation and stromal type. Hazard ratios (HR) and $95 \%$ confidence intervals (CI) were used to assess the independent contributions of significant factors. In all cases $\mathrm{P}<0.05$ was considered to indicate a statistically significant difference.

The patient survival time was measured from the date of surgery to mortality, related to any cause (without discrimination between mortalities resulting from lung carcinoma and other causes). Survival curves were created using the Kaplan-Meier method and compared using the log-rank test. All analyses were performed using the SPSS II statistical software package (version 19.0; SPSS, Inc., Chicago, IL, USA). 
Table I. Ki-67 LI and clinicopathological features of lung squamous cell carcinoma.

\begin{tabular}{|c|c|c|c|c|}
\hline \multirow[b]{2}{*}{ Variable } & \multirow[b]{2}{*}{ No. patients (\%) } & \multicolumn{2}{|c|}{ Ki-67 LI } & \multirow[b]{2}{*}{ P-value } \\
\hline & & $<30 \%$ & $\geq 30 \%$ & \\
\hline \multicolumn{5}{|l|}{ Age at surgery (years) } \\
\hline$<68$ & $45(50.6)$ & $6(13.3)$ & $39(86.7)$ & 0.370 \\
\hline$\geq 68$ & $44(49.4)$ & $9(20.5)$ & $35(79.5)$ & \\
\hline \multicolumn{5}{|l|}{ Gender } \\
\hline Male & $84(94.4)$ & $12(14.3)$ & $72(85.7)$ & 0.032 \\
\hline Female & $5(5.6)$ & $3(60.0)$ & $2(40.0)$ & \\
\hline \multicolumn{5}{|l|}{ Tumor size (mm) } \\
\hline$\leq 30$ & $34(38.2)$ & $8(23.5)$ & $26(76.5)$ & 0.186 \\
\hline$>30$ & $55(61.8)$ & $7(12.7)$ & $48(87.3)$ & \\
\hline \multicolumn{5}{|l|}{ Lymph node metastasis } \\
\hline $\mathrm{n}(-)$ & $62(69.7)$ & $12(19.4)$ & $50(80.6)$ & 0.539 \\
\hline $\mathrm{n}(+)$ & $27(30.3)$ & $3(11.1)$ & $24(88.9)$ & \\
\hline \multicolumn{5}{|l|}{ Lymphatic invasion } \\
\hline ly $(0,1)$ & $75(84.3)$ & $11(14.7)$ & $64(85.3)$ & 0.243 \\
\hline ly $(2,3)$ & $14(15.7)$ & $4(28.6)$ & $10(71.4)$ & \\
\hline \multicolumn{5}{|l|}{ Venous invasion } \\
\hline $\mathrm{v}(-)$ & $47(52.8)$ & $7(14.9)$ & $40(85.1)$ & 0.601 \\
\hline $\mathrm{v}(+)$ & $42(47.2)$ & $8(19.0)$ & $34(81.0)$ & \\
\hline \multicolumn{5}{|l|}{ Histological differentiation } \\
\hline Well, Mod & $81(91.0)$ & $14(17.3)$ & $67(82.7)$ & 1.000 \\
\hline Poor & $8(9.0)$ & $1(12.5)$ & $7(87.5)$ & \\
\hline \multicolumn{5}{|l|}{ Stromal type } \\
\hline Medullary, intermediate & $57(64.0)$ & $11(19.3)$ & $46(80.7)$ & 0.411 \\
\hline Scirrhous & $32(36.0)$ & $4(12.5)$ & $28(87.5)$ & \\
\hline \multicolumn{5}{|l|}{ Infiltration pattern } \\
\hline INFc (-) & $55(61.8)$ & $13(23.6)$ & $42(76.4)$ & 0.030 \\
\hline $\operatorname{INFc}(+)$ & $34(38.2)$ & $2(5.9)$ & $32(94.1)$ & \\
\hline
\end{tabular}

INF, tumor infiltration patterns; LI, labeling index; $\mathrm{n}(-)$, no lymph node metastasis; $\mathrm{n}(+)$, positive lymph node metastasis; ly $(0,1)$, no or mild lymphatic invasion; ly $(2,3)$, moderate or severe lymphatic invasion; v (-), no venous invasion; v (+), positive venous invasion; INFc(-), lung tissue specimen exhibited a clear boundary between tumor tissue and healthy surrounding tissue; INFc(+), cancer nests exhibited infiltrative growth and an unclear boundary between tumor tissue and surrounding healthy tissue.
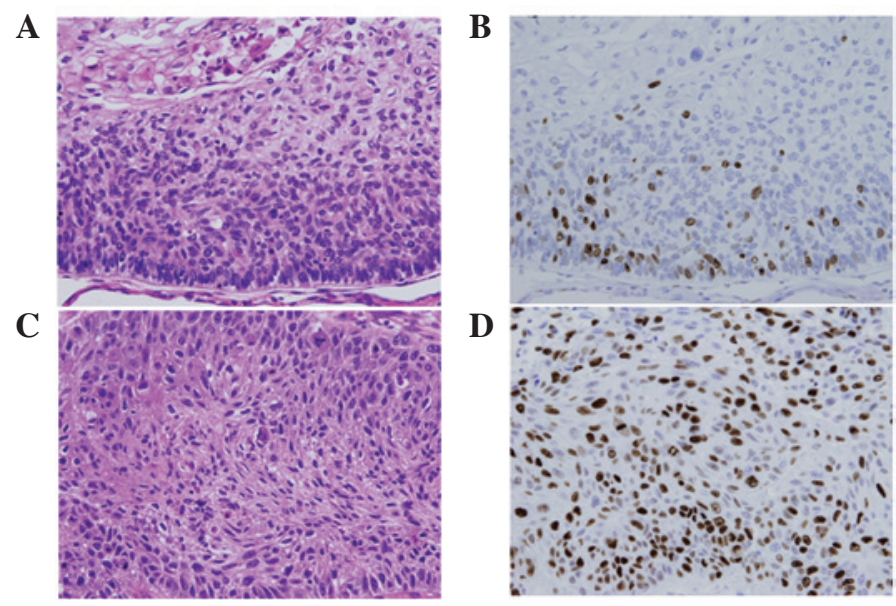

Figure 1. Immunoreactivity of the Ki-67 antibody in the nuclei of lung squamous cell carcinoma cells. (A) Low-grade cell proliferation, hematoxylin and eosin; (B) low-grade cell proliferation, LSAB method; (C) high-grade cell proliferation ( $\geq 30 \% \mathrm{Ki}-67 \mathrm{LI})$, hematoxylin and eosin; (D) high-grade cell proliferation ( $\geq 30 \%$ Ki-67 LI), LSAB method. X25. LI, labeling index; LSAB, labeled streptavidin-biotin. 
Table II. INF in lung squamous cell carcinoma patients.

\begin{tabular}{|c|c|c|c|c|}
\hline Variable & $\begin{array}{c}\text { Number } \\
\text { of patients }(\%)\end{array}$ & Hazard ratio & $\begin{array}{c}95 \% \text { Confidence } \\
\text { interval }\end{array}$ & P-value \\
\hline INF a & $10(11.2)$ & 0.991 & $0.392-2.507$ & 0.985 \\
\hline INF $a>b, a<b, b, b>c, b<c, c$ & $79(88.8)$ & & & \\
\hline INF $\mathrm{a}, \mathrm{a}>\mathrm{b}$ & $18(20.2)$ & 1.155 & $0.556-2.399$ & 0.699 \\
\hline INF $a<b, b, b>c, b<c, c$ & $71(79.8)$ & & & \\
\hline INF a, a $>b, a<b$ & $18(20.2)$ & 1.155 & $0.556-2.399$ & 0.699 \\
\hline INF $b, b>c, b<c, c$ & $71(79.8)$ & & & \\
\hline INF a, a $>b, a<b, b$ & $55(61.8)$ & 2.069 & $1.163-3.683$ & 0.013 \\
\hline INF $b>c, b<c, c$ & $34(38.2)$ & & & \\
\hline INF $a>b, a<b, b, b>c$ & $82(92.1)$ & 1.440 & $0.515-4.027$ & 0.487 \\
\hline INF b<c, c & $7(7.9)$ & & & \\
\hline INF $a>b, a<b, b, b>c, b<c$ & $85(95.5)$ & 1.171 & $0.283-4.841$ & 0.828 \\
\hline INF c & $4(4.5)$ & & & \\
\hline
\end{tabular}

INF, tumor infiltration patterns; INFa, cancer nests exhibited expanding growth and a clear boundary between tumor tissue and surrounding healthy tissue; INFb, cell growth and invasive patterns were intermediate between those of INFa and INFc; INFc, cancer nests exhibited infiltrative growth and no boundary between tumor tissue and surrounding healthy tissue.

Table III. Association between INFc(+) and clinicopathological factors (univariate analysis).

\begin{tabular}{|c|c|c|c|c|}
\hline Variable & No. of patients (\%) & Odds ratio & $\begin{array}{c}95 \% \text { Confidence } \\
\text { interval }\end{array}$ & P-value \\
\hline \multicolumn{5}{|l|}{ Age at surgery (years) } \\
\hline$<68$ & $45(50.6)$ & 1.845 & $0.776-4.388$ & 0.166 \\
\hline$\geq 68$ & $44(49.4)$ & & & \\
\hline \multicolumn{5}{|l|}{ Gender } \\
\hline Male & $84(94.4)$ & 1.083 & $0.172-6.839$ & 0.932 \\
\hline Female & $5(5.6)$ & & & \\
\hline \multicolumn{5}{|l|}{ Tumor size (mm) } \\
\hline$\leq 30$ & $34(38.2)$ & 0.816 & $0.340-1.961$ & 0.650 \\
\hline$>30$ & $55(61.8)$ & & & \\
\hline \multicolumn{5}{|l|}{ Lymph node metastasis } \\
\hline $\mathrm{n}(-)$ & $62(69.7)$ & 1.166 & $0.462-2.939$ & 0.745 \\
\hline $\mathrm{n}(+)$ & $27(30.3)$ & & & \\
\hline \multicolumn{5}{|l|}{ Lymphatic invasion } \\
\hline ly $(0,1)$ & $75(84.3)$ & 1.259 & $0.396-4.005$ & 0.697 \\
\hline ly $(2,3)$ & $14(15.7)$ & & & \\
\hline \multicolumn{5}{|l|}{ Venous invasion } \\
\hline $\mathrm{v}(-)$ & $47(52.8)$ & 2.615 & $1.085-6.305$ & 0.032 \\
\hline $\mathrm{v}(+)$ & $42(47.2)$ & & & \\
\hline \multicolumn{5}{|l|}{ Histological differentiation } \\
\hline Well, Mod & $81(91.0)$ & 0.000 & 0.000 & 0.999 \\
\hline Poorly & $8(9.0)$ & & & \\
\hline \multicolumn{5}{|l|}{ Stromal type } \\
\hline Medullary, intermediate & $57(64.0)$ & 6.462 & $2.483-16.817$ & $<0.001$ \\
\hline Scirrhous & $32(36.0)$ & & & \\
\hline \multicolumn{5}{|l|}{ Ki-67 LI } \\
\hline$<30 \%$ & $15(16.9)$ & 4.952 & $1.043-23.523$ & 0.044 \\
\hline$\geq 30 \%$ & $74(83.1)$ & & & \\
\hline
\end{tabular}

LI, labeling index; $\mathrm{n}(-)$, no lymph node metastasis; $\mathrm{n}(+)$, positive lymph node metastasis; ly $(0,1)$, no or mild lymphatic invasion; ly $(2,3)$, moderate or severe lymphatic invasion; $\mathrm{v}(-)$, no venous invasion; $\mathrm{v}(+)$, positive venous invasion; INFc(+), cancer nests exhibited infiltrative growth and an unclear border with the surrounding tissue. 
Table IV. Association between INFc(+) and clinicopathological factors (multivariate analysis).

\begin{tabular}{|c|c|c|c|}
\hline Variable & Odds ratio & $\begin{array}{l}95 \% \text { Confidence } \\
\text { interval }\end{array}$ & P-value \\
\hline \multicolumn{4}{|l|}{ Ki-67 LI } \\
\hline $\begin{array}{l}<30 \% \\
\geq 30 \%\end{array}$ & 12.543 & $1.531-102.777$ & 0.018 \\
\hline \multicolumn{4}{|l|}{ Stromal type } \\
\hline $\begin{array}{l}\text { Medullary, intermediate } \\
\text { Scirrhous }\end{array}$ & 8.402 & $2.923-24.147$ & $<0.001$ \\
\hline Propensity score & 0.025 & $0.000-1.349$ & 0.070 \\
\hline
\end{tabular}

Ki-67 LI: Ki-67 labeling index; INFc(+), cancer nests exhibited infiltrative growth and an unclear border between the tumor tissue surrounding healthy tissue.

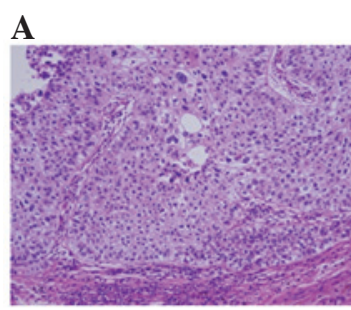

INF a

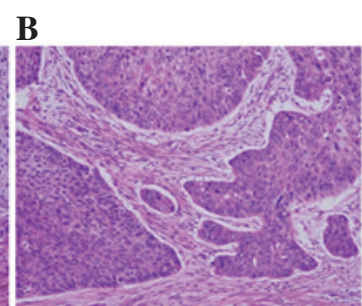

INF b

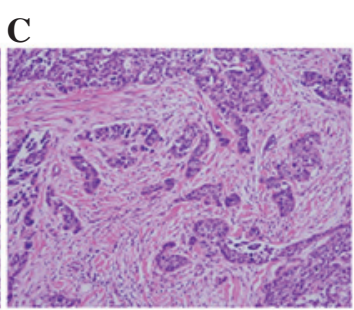

INF C

Figure 2. Lung squamous cell carcinoma (hematoxylin and eosin). INF at the invasive front was classified into three groups: (A) INFa, cancer nests exhibited expanding growth and a distinct border between tumor tissue and surrounding healthy tissue. (B) INFb, growth and invasive patterns were intermediate between those of INFa and INFc. (C) INFc, cancer nests exhibited infiltrative growth and an unclear boundary between tumor cells and surrounding healthy tissue. INF, tumor infiltration patterns.

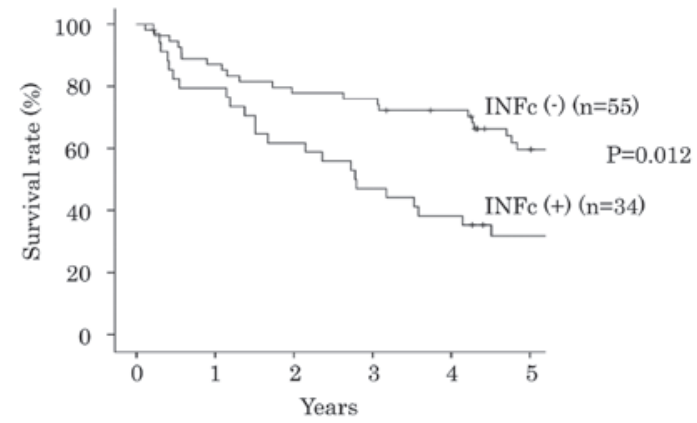

Figure 3. Tumor infiltration patterns and cumulative survival of patients with lung squamous cell carcinoma. INFc, cancer nests exhibited infiltrative growth and an unclear boundary between tumor tissue and surrounding healthy tissue. INF, tumor infiltration patterns.

\section{Results}

Lung SqCC cell proliferation. High-grade cell proliferation $(\geq 30 \% \mathrm{Ki}-67 \mathrm{LI})$ and low-grade cell proliferation $(<30 \%$ Ki-67 LI) was observed in $16.9 \%(15 / 89)$ and $83.1 \%(74 / 89)$ of SqCC lung cancer specimens, respectively (Fig. 1). Associations between Ki-67 LI and clinicopathological features are summarized in Table I. INFc(+) was most common in SqCC lung cancer specimens with high-grade cell proliferation ( $\geq 30 \% \mathrm{Ki}-67 \mathrm{LI}$ ) compared with those with low-grade cell proliferation $(<30 \% \mathrm{Ki}-67 \mathrm{LI} ; \mathrm{P}=0.03)$. However, no significant difference was detected in prognosis between the high and low Ki-67 LI groups.

Tumor growth patterns of lung SqCC. Lung tissue specimens were initially categorized into three INF groups (Fig. 2). They were further classified into seven groups based on the INF of each specimen: INFa $(10,11.2 \%), \operatorname{INFa}>b(8,9.0 \%), \mathrm{INFa}<\mathrm{b}$ $(0,0 \%), \operatorname{INFb}(37,41.6 \%), \operatorname{INFb}>\mathrm{c}(27,30.3 \%), \operatorname{INFb}<\mathrm{c}(3,3.4 \%)$ and INFc $(4,4.5 \%)$. The patients with INFc(+) $(\mathrm{INFb}>\mathrm{c}, \mathrm{b}<\mathrm{c}, \mathrm{c})$ had a poor outcome, compared with the patients with INFc(-) (INFa, $\mathrm{a}>\mathrm{b}, \mathrm{a}<\mathrm{b}, \mathrm{b})$ (Table II). The associations between $\mathrm{INFc}(+)$ and clinicopathological features of patients with lung SqCC according to a univariate analysis, are summarized in Table III. INFc(+) was significantly associated with venous invasion ( $\mathrm{P}=0.032$; HR, 2.615; 95\% CI, 1.085-6.305), stromal type $(\mathrm{P}<0.001 ; \mathrm{HR}, 6.462 ; 95 \% \mathrm{CI}, 2.483-16.817)$ and $\mathrm{Ki}-67 \mathrm{LI}$ $(\mathrm{P}=0.044$; HR, 4.952; 95\% CI, 1.043-23.523) of lung SqCC. INFc(+) cases exhibited a significantly poorer prognosis compared with INFc (-) cases ( $\mathrm{P}=0.012$; Fig. 3).

Multivariate analyses for prediction of INFc. Propensity scores were calculated by measuring the effect of the following covariates on $\operatorname{INFc}(+)$ : Age at surgery, gender, tumor size, lymph node metastasis, lymphatic invasion, histological differentiation and stromal type. Multivariate logistic regression analysis demonstrated that $\mathrm{INFc}(+)$ was significantly associated with Ki-67 LI (odds ratio, 12.5; 95\% CI, 1.5-102.8; $\mathrm{P}=0.018$ ) and 
stromal type (odds ratio, 8.4; 95\%, CI, 2.9-24.1; $\mathrm{P}<0.001$ ) following adjustment for the propensity score (Table IV).

\section{Discussion}

As a result of the advances in imaging, diagnostic techniques and operative procedures, the number of patients with lung SqCC undergoing surgical resection has increased for the last three decades. In the present study, 89 surgically resected specimens of lung tissue from patients with lung SqCC were analyzed in order to investigate tumor aggressiveness. INF and local tumor proliferation in lung SqCC were analyzed by measuring cell proliferation, using $\mathrm{Ki}-67$ expression as a proxy. $\mathrm{INFc}(+)$ was most common in the lung tissue samples from cases with high-grade cell proliferation $(\mathrm{Ki}-67 \mathrm{LI} \geq 30 \%)$ compared with those from cases with low grade cell proliferation (Ki-67 LI $<30 \%)$. To the best of our knowledge, this is the first report of an association between INF and lung SqCC cell proliferation.

A previous study demonstrated a correlation between the survival rate of patients with lung $\mathrm{SqCC}$, and tumor budding and histological aggressiveness (24). In the present study, a significantly greater number of $\mathrm{INFc}(+)$ lung $\mathrm{SqCC}$ specimens exhibited high-grade than low-grade cell proliferation. These results suggest that high-grade cell proliferation may affect the infiltrative growth of cancer nests. Furthermore, $\operatorname{INFc}(+)$ was significantly associated with the scirrhous stromal type and positive venous invasion (Table III).

A number of meta-analyses have addressed the prognostic value of Ki-67 in lung cancer. However its clinicopathological role remains to be elucidated (28-34). Ciancio et al (9) demonstrated that Ki-67 immunostaining of lung tissue specimens obtained from patients with non-small cell lung cancer (NSCLC) using fiber-optic bronchoscopy, may be useful for making prognostic predictions for patients with lung SqCC. Ciancio et al (9) demonstrated that $42.1 \%$ of the lung cancer cases exhibited high-grade cell proliferation (Ki-67 LI > 25\%). By contrast, the present study demonstrated that $83.1 \%$ of SqCC lung cancer specimens exhibited high-grade cell proliferation (Ki-67 LI > 30\%). The present study analyzed lung cancer tissues taken from surgical resection, and therefore examined entire tumor, whereas the investigation of Ciancio et al (9) used lung cancer specimens obtained by biopsy. It is hypothesized that the different procedure used for obtaining the specimens (biopsy vs. surgical resection) between Ciancio et al (9) and the present study, may explain the contrasting results in the percentage of lung cancer specimens exhibiting high-grade cell proliferation. Furthermore, Ciancio et al (9) examined Ki-67 overexpression in NSCLC cells and the clinical outcomes for patients with NSCLC, which included SqCC, adenocarcinoma and other histological types. By contrast, the present study focussed on SqCC lung tissue. In terms of patient survival, the results of the present study are in accordance with the conclusions of Ciancio et al (9). The present study demonstrated that $\operatorname{INFc}(+)$ may be a prognostic factor in SqCC. However, further investigations are required in order to examine the molecular and histological associations between tumor invasiveness and high-grade cell proliferation in lung SqCC.

In conclusion, high-grade cell proliferation, as measured by Ki-67 LI, significantly correlated with an INF that indi- cated a more aggressive lung SqCC. Ki-67 LI may therefore be used as an indicator of $\operatorname{INFc}(+)$ and is a potential prognostic factor for lung SqCC.

\section{Acknowledgements}

The authors would like to thank Professor Hiroyuki Kobayashi (Department of Clinical Pharmacology, Tokai University School of Medicine, Isehara, Kanagawa) for help with the statistical analysis.

\section{References}

1. Ferlay J, Shin HR, Bray F, Forman D, Mathers C and Parkin DM: Estimates of worldwide burden of cancer in 2008: GLOBOCAN 2008. Int J Cancer 127: 2893-2917, 2010.

2. Beadsmoore CJ and Screaton NJ: Classification, staging and prognosis of lung cancer. Eur J Radiol 45: 8-17, 2003.

3. Goldstraw P, Crowley J, Chansky K, et al: The IASLC Lung Cancer Staging Project: proposals for the revision of the TNM stage groupings in the forthcoming (seventh) edition of the TNM classification of malignant tumours. J Thorac Oncol 2: 706-714, 2007.

4. Hong J, Kyung SY, Lee SP, et al: Pemetrexed versus gefitinib versus erlotinib in previously treated patients with non-small cell lung cancer. Korean J Intern Med 25: 294-300, 2010.

5. Rossi A, Ricciardi S, Maione P, de Marinis F and Gridelli C: Pemetrexed in the treatment of advanced non-squamous lung cancer. Lung Cancer 66: 141-149, 2009.

6. Sandler A, Gray R, Perry MC, et al: Paclitaxel-carboplatin alone or with bevacizumab for non-small-cell lung cancer. N Engl J Med 355: 2542-2550, 2006.

7. Reck M, von Pawel J, Zatloukal P, et al: Phase III trial of cisplatin plus gemcitabine with either placebo or bevacizumab as first-line therapy for nonsquamous non-small-cell lung cancer: AVAil. J Clin Oncol 27: 1227-1234, 2009.

8. Rosell R, Perez-Roca L, Sanchez JJ, et al: Customized treatment in non-small-cell lung cancer based on EGFR mutations and BRCA1 mRNA expression. PLoS One 4: e5133, 2009.

9. Ciancio N, Galasso MG, Campisi R, Bivona L, Migliore M and Di Maria GU: Prognostic value of p53 and Ki67 expression in fiberoptic bronchial biopsies of patients with non small cell lung cancer. Multidiscip Respir Med 7: 29, 2012

10. Kosacka M, Piesiak P, Kowal A, Gołecki M and Jankowska R: Galectin-3 and cyclin D1 expression in non-small cell lung cancer. J Exp Clin Cancer Res 30: 101, 2011.

11. Sterlacci W, Fiegl M, Hilbe W, et al: Deregulation of p27 and cyclin D1/D3 control over mitosis is associated with unfavorable prognosis in non-small cell lung cancer, as determined in 405 operated patients. J Thorac Oncol 5: 1325-1336, 2010.

12. Lei B, Liu S, Qi W, et al: PBK/TOPK expression in non-small-cell lung cancer: its correlation and prognostic significance with Ki67 and p53 expression. Histopathology 63: 696-703, 2013.

13. Motadi LR, Bhoola KD and Dlamini Z: Expression and function of retinoblastoma binding protein 6 (RBBP6) in human lung cancer. Immunobiology 216: 1065-1073, 2011.

14. Cattoretti G, Becker MH, Key G, et al: Monoclonal antibodies against recombinant parts of the Ki-67 antigen (MIB 1 and MIB 3) detect proliferating cells in microwave-processed formalin-fixed paraffin sections. J Pathol 168: 357-363, 1992.

15. Gerdes J, Li L, Schlueter C, et al: Immunobiochemical and molecular biologic characterization of the cell proliferation-associated nuclear antigen that is defined by monoclonal antibody Ki-67. Am J Pathol 138: 867-873, 1991.

16. Hui AM, Shi YZ, Li X, et al: Proliferative marker Ki-67 in gallbladder carcinomas: high expression level predicts early recurrence after surgical resection. Cancer Lett 176: 191-198, 2002.

17. Xuan YH, Choi YL, Shin YK, et al: An immunohistochemical study of the expression of cell-cycle-regulated proteins $\mathrm{p} 53$, cyclin D1, RB, p27, Ki67 and MSH2 in gallbladder carcinoma and its precursor lesions. Histol Histopathol 20: 59-66, 2005.

18. Haraguchi M, Yamamoto M, Saito A, et al: Prognostic value of depth and pattern of stomach wall invasion in patients with an advanced gastric carcinoma. Semin Surg Oncol 10: 125-129, 1994. 
19. Japanese Classification of Gastric Carcinoma - 2nd English Edition. Gastric Cancer 1: 10-24, 1998.

20. Maehara Y, Oshiro T, Adachi Y, Ohno S, Akazawa K and Sugimachi K: Growth pattern and prognosis of gastric cancer invading the subserosa. J Surg Oncol 55: 203-208, 1994.

21. Okada K, Kijima H, Imaizumi T, et al: Wall-invasion pattern correlates with survival of patients with gallbladder adenocarcinoma. Anticancer Res 29: 685-691, 2009.

22. Song KY, Hur H, Jung CK, et al: Impact of tumor infiltration pattern into the surrounding tissue on prognosis of the subserosal gastric cancer (pT2b). Eur J Surg Oncol 36: 563-567, 2010.

23. Kong KY, Park JY, Kim DY, et al: Prognostic significance of stromal microinvasion in the intestinal type of ovarian mucinous adenocarcinoma. Ann Surg Oncol 18: 3462-3468, 2011.

24. Masuda R, Kijima H, Imamura N, et al: Tumor budding is a significant indicator of a poor prognosis in lung squamous cell carcinoma patients. Mol Med Rep 6: 937-943, 2012.

25. Sobin LH, Gospodarowicz MK and Wittekind C (eds): TNM Classification of Malignant Tumors. 7th edition. Wiley, Hoboken, New Jersey, NJ, USA, 2010.

26. Travis WD, Brambilla E, Muller-Hermedin HK and Harris CC (eds): Pathology and Genetics. Tumours of the Lung, Pleura, Thymus and Heart. IARC Press, Lyon, France, 2004.

27. Kawano $\mathrm{K}$ and Yanagisawa S: Predictive value of laminin-5 and membrane type 1-matrix metalloproteinase expression for cervical lymph node metastasis in T1 and T2 squamous cell carcinomas of the tongue and floor of the mouth. Head Neck 28 : $525-533,2006$
28. Soomro IN and Whimster WF: Growth fraction in lung tumours determined by Ki67 immunostaining and comparison with AgNOR scores. J Pathol 162: 217-222, 1990.

29. Scagliotti GV, Micela M, Gubetta L, et al: Prognostic significance of Ki67 labelling in resected non small cell lung cancer. Eur J Cancer 29A: 363-365, 1993.

30. Hommura F, Dosaka-Akita H, Mishina T, et al: Prognostic significance of p27KIP1 protein and ki-67 growth fraction in non-small cell lung cancers. Clin Cancer Res 6: 4073-4081, 2000.

31. Nguyen VN, Mirejovský P, Mirejovský T, Melinova L and Mandys V: Expression of cyclin D1,Ki-67 and PCNA in non-small cell lung cancer: prognostic significance and comparison with p53 and bcl-2. Acta Histochem 102: 323-338, 2000.

32. Maddau C, Confortini M, Bisanzi S, et al: Prognostic significance of p53 and Ki-67 antigen expression in surgically treated non-small cell lung cancer: immunocytochemical detection with imprint cytology. Am J Clin Pathol 125: 425-431, 2006.

33. Ishida $\mathrm{H}$, Irie $\mathrm{K}$, Itoh $\mathrm{T}$, Furukawa $\mathrm{T}$ and Tokunaga $\mathrm{O}$ : The prognostic significance of $\mathrm{p} 53$ and bcl-2 expression in lung adenocarcinoma and its correlation with Ki-67 growth fraction. Cancer 80: 1034-1045, 1997.

34. Martin B, Paesmans M, Mascaux C, et al: Ki-67 expression and patients survival in lung cancer: systematic review of the literature with meta-analysis. Br J Cancer 91: 2018-2025, 2004. 